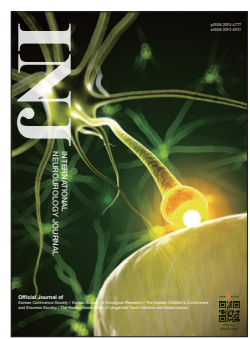

\title{
Commentary on "Cognitive Function and Urologic Medications for Lower Urinary Tract Symptoms"
}

\author{
Lori Birder ${ }^{1,2}$ \\ ${ }^{1}$ Department of Medicine, School of Medicine, University of Pittsburgh, Pittsburgh, PA, USA \\ ${ }^{2}$ Department of Pharmacology and Chemical Biology, University of Pittsburgh, Pittsburgh, PA, USA
}

This review discusses the correlation of various urologic medications and the possible effect on cognitive function in the older population [1]. This is extremely important considering the number of medications (including over the counter) that are prescribed for the older patient. For example, the authors subclassified anticholinergic medications according reports affecting cognitive function in patients [1]. Though useful information, further studies are needed to determine whether the risk for dementia taking these medications may differ in middleaged versus the older patient. Further, the increased reliance on various types of over the counter medications (such as sleeping aids, many of which may mimic anticholinergic effects) may increase drug-drug interactions and in turn, risk of cognitive dysfunction [2]. It has been shown that patients diagnosed with dementia treated with cholinesterase inhibitors as well as antimuscarinics are likely to have a faster rate of cognitive decline [3]. The review discusses a number of drug classes (i.e., anticholinergics, alpha blockers, beta 3 agonists, 5 alpha-reductase inhibitor) but as the authors pointed out, it is unclear in many cases if long-term use increases the risk of dementia. Another unknown is whether adverse events can be reversed or normalized if the treatment is stopped [4]. The benefit or risk in each category is reviewed as seniors are at a higher risk to adverse events due to age-associated changes in drug metabolism, as well as the changes in the blood-brain barrier [5]. Overall, a better understanding of age-associated drug-drug interactions and a discussion of risks versus benefits of a medication is needed to reduce the incidence of long-term side effects in the older patient.
- Conflict of Interest: No potential conflict of interest relevant to this article was reported.

\section{REFERENCES}

1. Kim YJ, Tae BS, Bae JH. Cognitive function and urologic medications for lower urinary tract sym.ptoms. Int Neurourol J 2020;24:23140.

2. Green AR, Segal J, Tian J, Oh E, Roth DL, Hilson L, et al. Use of bladder antimuscarinics in older adults with impaired cognition. J Am Geriatr Soc 2017;65:390-4.

3. Sink KM, Thomas J, Xu H, Craig B, Kritchevsky S, Sands LP. Dual use of bladder anticholinergics and cholinesterase inhibitors: longterm functional and cognitive outcomes. J Am Geriatr Soc 2008;56: 847-53.

4. Campbell NL, Boustani MA. Adverse cognitive effects of medications: turning attention to reversibility. JAMA Int Med 2015;175: 408-9.

5. LeCouteur DG, Mclachlan AJ, de Cabo R. Aging, drugs and drug metabolism. J Gerontology 2012;67:137-9.
Corresponding author: Lori Birder (iD https://orcid.org/0000-0002-3393-2256 Department of Medicine, School of Medicine, University of Pittsburgh, A1219 Scaife Hall, Pittsburgh, PA 15261, USA

E-mail: lbirder@pitt.edu

Submitted: August 11, 2020 / Accepted after revision: August 23, 2020 (i) $\$$ This is an Open Access article distributed under the terms of the Creative Commons Attribution Non-Commercial License (https://creativecommons.org/licenses/by-nc/4.0/) which permits unrestricted non-commercial use, distribution, and reproduction in any medium, provided the original work is properly cited. 